\title{
Male sexual dysfunction and infertility associated with neurological disorders
}

\begin{abstract}
Mikkel Fode ${ }^{1}$, Sheila Krogh-Jespersen ${ }^{2}$, Nancy L Brackett ${ }^{3}$, Dana A Ohl ${ }^{4}$, Charles M Lynne ${ }^{5}$ and Jens Sønksen ${ }^{1}$
Normal sexual and reproductive functions depend largely on neurological mechanisms. Neurological defects in men can cause infertility through erectile dysfunction, ejaculatory dysfunction and semen abnormalities. Among the major conditions contributing to these symptoms are pelvic and retroperitoneal surgery, diabetes, congenital spinal abnormalities, multiple sclerosis and spinal cord injury. Erectile dysfunction can be managed by an increasingly invasive range of treatments including medications, injection therapy and the surgical insertion of a penile implant. Retrograde ejaculation is managed by medications to reverse the condition in mild cases and in bladder harvest of semen after ejaculation in more severe cases. Anejaculation might also be managed by medication in mild cases while assisted ejaculatory techniques including penile vibratory stimulation and electroejaculation are used in more severe cases. If these measures fail, surgical sperm retrieval can be attempted. Ejaculation with penile vibratory stimulation can be done by some spinal cord injured men and their partners at home, followed by in-home insemination if circumstances and sperm quality are adequate. The other options always require assisted reproductive techniques including intrauterine insemination or in vitro fertilization with or without intracytoplasmic sperm injection. The method of choice depends largely on the number of motile sperm in the ejaculate.
\end{abstract}

Asian Journal of Andrology (2012) 14, 61-68; doi:10.1038/aja.2011.70; published online5 December 2011

Keywords: assisted reproductive techniques; ejaculation; electroejaculation; erectile dysfunction; infertility; nervous system diseases; penile vibratory stimulation; retrograde ejaculation; surgical sperm retrieval

\section{INTRODUCTION}

Male reproductive functioning is highly dependent on the neurological integrity of the pelvic floor and the spinal cord. Erectile function and ejaculation are diminished in patients with neurological damage from conditions including spinal cord injury (SCI), diabetes mellitus, multiple sclerosis (MS), congenital disorders of the spinal cord and trauma or surgery. Furthermore, neurological problems can cause impairments in sperm quality, which is most often seen in spinal cord-injured men.

Normal erectile function

Erections are initiated by a combination of psychic and physical stimuli, and erectile function is controlled by parasympathetic fibers originating from S2 to $\mathrm{S} 4$. These fibers travel through the pelvic nerve and the pelvic plexus to the cavernous nerve, which enters the corpora cavernosa. ${ }^{1}$ As these fibers pass through the pelvis, the nerves run in close proximity to the prostate and rectum, which makes them prone to injury during surgical procedures. When activated, the cavernous nerves release nitric oxide and acetylcholine, both of which induce relaxation of the smooth muscle tissue by inducing cyclic guanosine monophosphate and cyclic adenosine monophosphate, respectively, which in turn results in calcium efflux. This process causes a massive influx of blood to the tissue. Through a shear stress mechanism induced by this blood flow, the endothelium in the penis releases more nitric oxide that causes an erection to reach a maximum and then maintains that erection. ${ }^{2}$ Increased intracavernosal pressure then compresses the small venules, which results in blood trapping and contributes to maintaining the erection. The activation of basic sympathetic tone following sexual activity results in the contraction of smooth muscle, which results in the penis returning to a flaccid state. Moreover, phosphodiesterase 5 (PDE5), which is abundant in the penile tissue, contributes to this process by breaking down cyclic guanosine monophosphate.

Ejaculatory function

Like erection, ejaculation is the result of coordination of both psychological and physical sexual stimulation. The ejaculatory reflex is coordinated by the spinal cord and depends on thoracolumbar sympathetic fibers from segments T10-L2 and somatic fibers from segments S2-S4. This reflex receives its somatic input primarily from the dorsal nerve of the penis, which is activated by stimulation of the glans penis. Neurons in the cortex, thalamus, hypothalamus, midbrain and pons, all play a role in ejaculation; however, their exact functions are poorly understood. ${ }^{3,4}$

Prior to ejaculation, sperm that are stored in the epididymis are transported to the vas deferens by means of contractions of smooth 
muscle tissue. This is followed by coordinated contractions of the vas mediated by the sympathetic fibers. ${ }^{5}$ The contractions move sperm through the vas to the ejaculatory ducts, which also have an inlet from the seminal vesicles. ${ }^{6}$ Along with seminal plasma from the seminal vesicles and prostate, the sperm are then transported to the urethra from which they are expelled in a projectile manner as somatic nerve fibers induce rhythmic contractions of the pelvic/periurethral muscles. During ejaculation, the bladder neck closes and the external urethral sphincter opens. This mechanism is coordinated by the sympathetic fibers and prevents retrograde ejaculation into the bladder.,

Given that erection and ejaculation are separate events and that the neurons responsible for the two events are different, ejaculation can occur without the presence of an erection and erections can be present without the ability to ejaculate.

\section{Erectile and ejaculatory function in patients with neurological damage}

The disruption of any of the neural features described above can cause erectile and/or ejaculatory dysfunction. Therefore, the systems are very susceptible to neurological damage, with a number of different conditions having the ability to disrupt them.

Erectile dysfunction (ED) is the inability to achieve or maintain an erection that is sufficiently rigid for achieving satisfying sexual intercourse $^{8}$ and it is either partial or complete depending on the extent of neurological damage.

Ejaculatory dysfunction may take different forms, including premature ejaculation, retrograde ejaculation, anejaculation and delayed ejaculation. The latter three are associated with neurological defects. In retrograde ejaculation, all or part of the ejaculate reaches the bladder instead of being expelled through the urethral meatus. This condition is caused by a malfunction in the bladder neck closure secondary to dysfunction of the sympathetic nerves, which control this mechanism. ${ }^{9}$ Retrograde ejaculation causes the post-ejaculatory urine to be cloudy and is ultimately diagnosed when sperm are present in the bladder or urine after ejaculation. ${ }^{10}$ Anejaculation is a complete lack of both antegrade and retrograde ejaculate. SCI is the most common neurological cause of anejaculation. ${ }^{11}$ Delayed ejaculation is a less severe condition in which ejaculation can occur at a higher threshold of stimulation than normally needed. ${ }^{10}$

\section{NEUROLOGICAL DEFECTS}

\section{Surgery/trauma}

Both pelvic trauma and pelvic surgery can cause direct damage to the pelvic floor nerves and disrupt neurological mechanisms responsible for erection and ejaculation. While prostatectomies and cystectomies certainly can cause nerve damage, their influence on anejaculation is due to more than just neurological reasons, as accessory sexual glands and semen pathways are removed during these surgeries. Rectal surgery can create problems due to damage of the peripheral nerves and to damage of the superior hypogastric plexus. Thus, ED is seen in $36 \%-$ $60 \%$ of patients after radical rectal surgery. ${ }^{12}$ Other types of surgeries can cause damage to the lumbar sympathetic ganglia, the superior hypogastric plexus and fibers from both of these structures. These surgeries include periaortic surgeries, such as aneurism or bypass procedures, trauma surgery, any retroperitoneal lymph node samplings, and, in particular, retroperitoneal lymph node dissection in conjunction with testicular cancer. The classical retroperitoneal lymph node dissection removes post-ganglionic sympathetic nerves and the hypogastric plexus, which are necessary in normal ejaculation. Nervesparing retroperitoneal lymph node dissection has been developed to preserve these structures and has shown excellent results. However, high rates of post-surgical ejaculatory dysfunction are still evident with high tumor burdens or surgery after chemotherapy. ${ }^{11}$

\section{Diabetes}

Diabetes causes disruption of sexual function via the following two mechanisms: autonomic neuropathy, which causes ED and ejaculatory dysfunction, and concurrent vascular disease, which is a major cause of ED.

ED affects $35 \%-75 \%$ of type 1 diabetic males ${ }^{13}$ and ejaculatory dysfunction is estimated to be present in approximately $40 \%$ of this group. ${ }^{14}$ Ejaculatory dysfunction can exhibit a slow progressive decline from a decreased amount of ejaculate-to-retrograde ejaculation to anejaculation depending on the degree of sympathetic autonomic neuropathy involved. ${ }^{14,15}$ As with other long-term complications of diabetes, the occurrence of these conditions is related to how well the patient's blood sugar is controlled. ${ }^{16}$

Furthermore, semen volume has been shown to be reduced in patients with diabetes (both types 1 and 2) compared to normal controls. ${ }^{17-22}$ Results regarding morphology and motility are conflicting, even though most studies find one or both of these parameters reduced. ${ }^{18-20,22}$ Also, increased sperm DNA damage has been detected in diabetic patients. ${ }^{17}$ Potential mechanisms behind the altered semen parameters in diabetic patients include endocrine disruption with reduced testosterone production and oxidative stress. ${ }^{23}$ The reduced semen volume may be caused by neurological damage as atony of the seminal vesicles has been shown in infertile diabetic patients with neuropathy. ${ }^{24}$

Both the sexual dysfunction and the potentially reduced semen quality can cause infertility. While the topic is still controversial, infertility has been found to be more prevalent in diabetic men than in nondiabetic controls, ${ }^{25}$ and a recent retrospective analysis has found a high prevalence of subfertility (51\%) among men with diabetes, ${ }^{26}$ thus highlighting the possible link between diabetes and infertility.

\section{Congenital spinal abnormalities}

Neural tube defects are congenital disorders of the spinal cord. The lumbar vertebrae are involved in more than $90 \%$ of cases, and the lower thoracic vertebrae in another $5 \%$ of cases. ${ }^{27}$ Most patients with these conditions have some kind of sexual dysfunction. Surgical treatment of these conditions can be a separate cause of neurological damage that creates further sexual dysfunction. ${ }^{28}$ The highest likelihood of becoming a father is found in men with lower and less severe damage. ${ }^{29}$ Sometimes, patients with lifelong ejaculatory dysfunction are found to have an occult dysplasia of the lower spinal cord, possibly with tethered cord syndrome.

\section{MS}

MS is a demyelinating disease of unknown etiology that affects the central nervous system - both the brain and the spinal cord. ${ }^{30}$ The course of this condition varies; however, it usually progresses and increases in severity over time. Its effect on sexual function depends on the location of plaques in the central nervous system with the degree of sexual dysfunction not necessarily correlating to the duration of the condition. ${ }^{31}$ ED may be present in approximately $73 \%$ of men and ejaculatory dysfunction in about $50 \%$ of men with this condition. ${ }^{32}$ Reduced libido is reported in about $40 \% .^{32}$

Little research has been done to access fertility and the semen quality of male MS patients. However, a study from 2008 clearly points to reduced sperm counts, reduced sperm motility and altered sperm 
morphology in MS patients compared to normal controls. ${ }^{33}$ The diminished semen quality was particularly pronounced in patients with progressive disease. Possible explanations for the findings include a disturbed hypothalamus-pituitary-testis axis with reduced levels of sex hormones due to neurological damage, as well as reduced hormone production due to chronic inflammation. In addition to sexual dysfunction and reduced semen quality caused by the disease, MS patients may have reduced fertility as a consequence of adverse effects from their treatment. ${ }^{34}$

\section{SCI}

SCI induce a disruption of the nerve supply responsible for erectile function and ejaculation, which commonly causes both ED and anejaculation. Only about $9 \%$ of SCI men can ejaculate through masturbation or sexual intercourse. ${ }^{35}$ In addition, SCI can cause semen abnormalities in the form of low sperm motility and low sperm viability. ${ }^{36}$ Factors in sperm transportation/storage, the seminal plasma, ${ }^{37-39}$ and the immune system ${ }^{40-45}$ have recently emerged as the most likely explanations for these abnormalities. Semen abnormalities are most likely to occur in SCI men who have complete lesions of the spinal cord. ${ }^{46}$ As this condition most often occurs in young men, ${ }^{4-51}$ fertility is a major concern for these patients.

Other courses of neurologically induced sexual dysfunction include various causes of peripheral neuropathy, transverse myelitis and vascular spine injuries.

\section{Management of ED}

Success of ED treatment depends on the degree of neurological damage. The least invasive method, which should be considered first line, is oral treatment with PDE5 inhibitors. It is a prerequisite that the patient has some residual nerve function to induce the erection. Therefore, the treatment is generally best in the early stages of progressive neurological disorders when only partial neurological damage is present. PDE5 inhibitors were shown to be effective in approximately $50 \%$ of diabetic men. ${ }^{52}$ In a small $(n=8)$ non-randomized study investigating spina bifida patients, $63 \%$ had improved erections with treatment. ${ }^{53}$ Also, men with SCI may benefit considerably from PDE5 inhibitor treatment. ${ }^{54-56}$

The second line therapy-which is often necessary in neurological disorders-is penile injection therapy in which vasoactive agents are injected into the cavernous tissue of the penis. This activates the cyclic adenosine monophosphate system and leads to calcium efflux, smooth muscle relaxation and an erectile response. Alprostadil, papaverine and phentolamine can be used for this purpose and the treatment has been shown to be effective in a number of neurological conditions, including MS, diabetes and SCI. ${ }^{57-61}$ It is important to note that in men with SCI, the denervated tissue tends to be very sensitive to intracavernous injection. This means that the treatment has a success rate of up to $95 \%$ and also that the risk of priapism is increased. ${ }^{60,61}$ Therefore, SCI patients should generally be treated with lower doses than non-SCI men. Intraurethral alprostadil can be attempted if injection therapy is unacceptable to the patient; however, this method is generally less effective. ${ }^{62}$

Vacuum constriction devices can also be used based on patient preference. These devices induce a negative pressure that pulls venous blood into the penis. A constriction band is then placed at the base of the penis to keep the blood there. Vacuum devices can cause discoloration of the penis, decrease in penile temperature, discomfort with ejaculation and reduced penile sensation, but for some patients, the method can be a satisfactory choice. This treatment has been shown to be effective in $75 \%$ of diabetic men and in $72 \%-93 \%$ of SCI men. ${ }^{63-66}$ In SCI men with reduced penile sensation, it is important to be aware of potential ischemic complications with prolonged use of vacuum devices. ${ }^{67}$

The third-line treatment for ED is penile implants, which can be rigid, semirigid and inflatable. Three-piece inflatable devices, consisting of two cylinders, a reservoir and a pump in the scrotum, are the most commonly used. Simpler devices can sometimes be an advantage in patients with decreased hand function, such as with some SCI patients. Penile implants may provide a benefit in keeping condom catheters in place, as well as provide stability for intermittent catheterization in SCI patients. Overall, the satisfaction rates are high and the complication rates are low with penile implants. However, infection rates are higher in diabetics than in the general patient population, ${ }^{68}$ and both infection rates and the number of mechanical failures are increased in SCI men. ${ }^{69,70}$ These problems should be considered carefully prior to inserting an implant.

\section{MANAGEMENT OF EJACULATORY DISORDERS}

\section{Retrograde ejaculation}

The initial management of retrograde ejaculation depends on the degree of neurological damage. The least invasive treatment consists of medications that can sometimes reverse the retrograde ejaculation. ${ }^{71}$ Sympathomimetic agents are used since they can induce a pharmacological stimulation of the receptors that are not being stimulated by normal neurological mechanisms. These agents cause a contraction of the bladder neck, which prevents the ejaculate from flowing into the bladder. These agents include imipramine, ephedrine, pseudoephedrine and phenylpropanolamine. ${ }^{11,71,72}$ Pharmacological treatment generally works best in the early stages of progressive neurological disorders, such as diabetes, ${ }^{72}$ or in incomplete peripheral lesions as can be seen after surgery or trauma. If the malfunction of the ejaculatory reflex is complete, as seen with SCI men, medications will, of course, have little effect. Drug treatment should be administered only around the time of ovulation in order to avoid unnecessary side effects. $^{71}$

If the retrograde ejaculation cannot be reversed by drugs, the next step is post-ejaculation bladder harvest of sperm. Both urine and the acidic environment in the bladder can damage sperm; ${ }^{73}$ thus, the bladder must be emptied prior to ejaculation. This is done by catheterization in which a sperm-friendly medium (e.g., sperm wash medium or Ham's F-10 medium) is also installed in the bladder. ${ }^{74}$ When ejaculation has taken place, the sperm are collected immediatelyagain by catheterization. Here, it is important to use a non-spermicidal lubricant and a plastic catheter, because sperm can adhere to silicone catheters. The sperm are then processed in order to be used in assisted reproductive procedures. ${ }^{75-77}$

\section{Anejaculation}

As with retrograde ejaculation, anejaculation caused by mild neurological disorders can sometimes be treated with sympathomimetic agents. ${ }^{11,71,72}$ In more serious disorders, assisted ejaculation consisting of penile vibratory stimulation (PVS) or electroejaculation (EEJ) can be employed. If these procedures fail, surgical sperm retrieval can be attempted.

\section{ASSISTED EJACULATION \\ PVS}

In PVS, a vibrator is used to mechanically induce an ejaculation in SCI men. The only commercially available device for PVS is the FERTI 
CARE vibrator (Multicept A/S, Frederiksberg, Denmark) that was developed for this purpose (Figure 1). It is important that stimulation be done with an exact amplitude and frequency $(2.5 \mathrm{~mm}$ and $100 \mathrm{~Hz}$ respectively). ${ }^{78}$ The device is placed on the glans penis through which it activates the dorsal nerve of the penis, which, as previously described, constitutes the afferent limb of the ejaculatory reflex. This, in turn, activates the efferent part of the reflex via the spinal cord and an antegrade ejaculation is initiated. ${ }^{79,80}$ PVS is then terminated and the ejaculate is collected in a non-spermicidal cup. The urethra is milked manually to retrieve as many sperm cells as possible.

It follows that both the afferent and efferent limbs of the reflex must be functioning for PVS to be successful. Because of this, men with SCI above the level of the reflex (meaning above T10) have an $88 \%$ success rate with PVS, whereas men with lower injuries below this level have only a $15 \%$ success rate. ${ }^{81,82}$ Disruption of the dorsal penile nerves terminates the reflex response. ${ }^{83}$ Finally, cortical inhibition can prevent the reflex response, which is the primary reason that this procedure is not feasible for all patients with neurological conditions. The best candidates for PVS are SCI men with complete lesions. Non-SCI patients receive limited benefits from this device.

When successful, PVS will usually induce an ejaculation within the first 2 min of stimulation. ${ }^{84}$ If this does not occur, subsequent attempts are made following a brief interruption of stimulation. Adverse reactions are rare, but given that patients with reduced or absent sensation of the glans may not notice bruises or abrasions from the stimulation, the skin should be inspected both before treatment and during breaks. Treatment should be withheld or performed very carefully when there is inflammation or severe irritation of the glans penis. If PVS is initially unsuccessful, an attempt to use two vibrators simultaneously ${ }^{85}$ or to use accessory abdominal electrical stimulation ${ }^{86}$ can be made. Oral administration of midodrine or a PDE5 inhibitor prior to PVS may also be beneficial. ${ }^{87-89}$ Patients are generally considered non-responders after two failed PVS attempts, at least 1 week apart, in which at least the two-vibrator technique has been attempted. However, patients with a recent injury may not respond readily due to the spinal shock phase and more attempts can be made usually 1-6 months after the injury.

Aside from the rare incidence of skin irritation from prolonged stimulation, PVS must be performed with caution in patients with a penile implant, as the vibrator may push the glans onto the implant. More importantly, PVS should not be administered to patients with severe cardiac disease or untreated hypertension because the procedure can cause a rise in blood pressure. ${ }^{88}$

Finally, PVS can induce an uninhibited sympathetic reflex response in patients with an injury at the T6 level or above. ${ }^{90}$ This reflex response creates a condition called autonomic dysreflexia (AD), which begins with presymptoms in the form of hypertension, headache, flushing and bradycardia and can result in stroke, seizure and death.

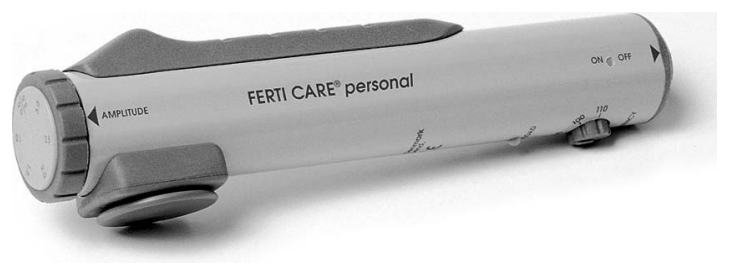

Figure 1 The FERTI CARE vibrator (Multicept A/S, Frederiksberg, Denmark) activates the ejaculatory reflex trough mechanical stimulation. The device allows for amplitude and frequency to be set at exactly $2.5 \mathrm{~mm}$ and $100 \mathrm{~Hz}$. This is essential in inducing ejaculation in $\mathrm{SCl}$ men. $\mathrm{SCl}$, spinal cord injury.
Patients who are prone to this condition will usually have experienced symptoms of an increased blood pressure in response to unpleasant stimuli below the level of their injury. In all patients, the physician should be aware of steep increases in blood pressure and presymptoms during stimulation. In patients assessed to be at risk of developing $\mathrm{AD}$, sublingual nifedipine, $20 \mathrm{mg}$, should be administered approximately 15 min prior to stimulation, as this can limit the increase in blood pressure. In subsequent PVS attempts, the dose can be adjusted based on the patient's response. ${ }^{91-93}$ If presymptoms occur or if the patient's blood pressure is noted to rise dramatically during PVS, the stimulation should be discontinued and the patient should be returned to an upright position.

\section{EEJ}

EEJ is a method in which an electrical current is used to induce ejaculation. This method is feasible with both SCI patients and with patients who have other causes of neurological anejaculation. The only Food and Drug Administration (FDA)-approved device for this procedure is the Seager Model 14 Electroejaculator (Dalzell Medical Systems, The Plains, VA, USA) (Figure 2). Ejaculation is induced by placing the patient in a lateral decubitus position and inserting the probe into the rectum with the electrodes facing the seminal vesicles and the prostate. The electrical current is then delivered in a wave-like pattern with $5 \mathrm{~s}$ of stimulation followed by rest periods of approximately $20 \mathrm{~s}$, during which ejaculation can occur. This often happens in a non-projectile, dribbling fashion and the ejaculate is collected during the procedure. It is important to milk the urethra to retrieve as much semen as possible. The first wave starts with $5 \mathrm{~V}$ and, in subsequent waves, voltage is progressively increased by $1-5 \mathrm{~V}$ until a maximum of $20-30 \mathrm{~V}$ is reached. Following each wave, the current is abruptly discontinued because this has been shown to increase the antegrade fraction of the ejaculate. ${ }^{94,95}$ The ejaculatory reflex is most likely activated by muscular contractions that are induced by the electricity. ${ }^{94}$ Stimulation is delivered until ejaculation is no longer induced-an

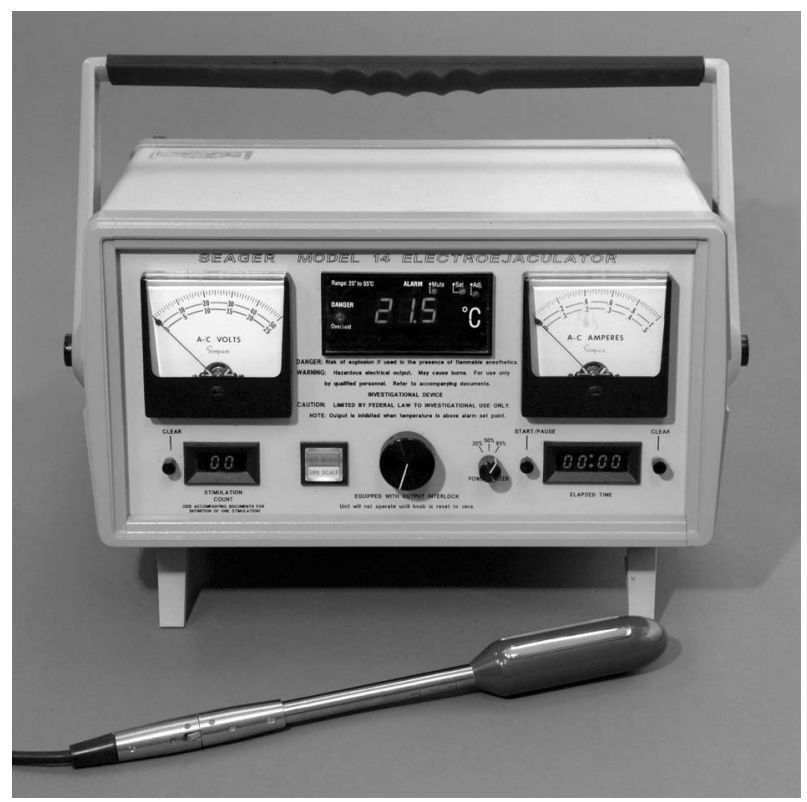

Figure 2 The Seager model 14 electroejaculator (Dalzell Medical Systems, The Plains, VA, USA) induces ejaculation by means of an electric current. This is done trough a rectal probe. The device has a built in thermometer to monitor rectal temperature during stimulation. 
indication that the system is empty. Up to 20 waves of stimulation may be necessary. Stimulation is of course stopped if the patient does not tolerate the procedure. Also, the Seager device has a built-in thermometer that will terminate the procedure if the rectal mucosa reaches a temperature above $38.5^{\circ} \mathrm{C}$.

EEJ is generally safe and is extremely effective in inducing ejaculation with a success rate of almost $100 \%$ in patients who can accept the procedure. ${ }^{81}$ However, it is more invasive, more demanding and more expensive than PVS, and it is less preferred by patients. ${ }^{96}$ EEJ always requires administration by a physician and both before and after the procedure rectoscopy must be performed to rule out any possible mucosal lesions. Also, SCI men with incomplete lesions and/or with preserved pelvic sensation as well as patients with other neurological conditions require general anesthesia during the procedure. ${ }^{97,98}$ Finally, EEJ usually results in a lower total motile sperm count than PVS $^{96,99}$ and there is often a significant amount of retrograde ejaculation after which sperm must be collected as described previously.

In the largest case series of its kind, EEJ was performed 953 times in 210 SCI patients for an average of 4.5 trials per patient. Altogether 897 of the $953 \mathrm{EEJ}$ trials $(94.1 \%)$ resulted in ejaculation and in about $90 \%$ of cases the ejaculate contained spermatozoa which could be used for either a simple insemination procedure or one of the more complicated assisted reproductive techniques (ARTs, see below). ${ }^{35}$ When a second trial of EEJ was attempted after a finding of azoospermia on the first attempt, the second EEJ resulted in semen with sperm in a third of the patients. ${ }^{100}$

Contraindications of EEJ include lesions/inflammation of the rectum and bleeding disorders as well as anticoagulation therapy. As EEJ's effects on pacemakers are unknown, these are a relative contraindication. As with PVS, EEJ can cause AD in patients with an injury at or above T6. This condition is prevented by pre-treatment with nifedipine as described above. Also, patients undergoing EEJ must be monitored carefully and monitoring of blood pressure in patients under general anesthesia is an absolute requirement.

\section{Surgical sperm retrieval methods}

If sperm cannot be obtained with assisted ejaculation, then sperm retrieval can be attempted either by aspiration or through surgical exploration. These are invasive procedures in which sperm are collected directly from the epididymis or from the testis. Sperm retrieval methods were developed to retrieve sperm from azoospermic men and should generally not be the first choice in anejaculation, as both PVS and EEJ are cheaper, less invasive, and result in a higher motile sperm count. At least in SCI men, it may even be reasonable to obtain a second ejaculate by EEJ in men who are azoospermic on their first ejaculate before proceeding to sperm retrieval, as the second ejaculate will sometimes contain live spermatozoa. ${ }^{100}$ However, in neurological anejaculation, which is refractory to assisted ejaculation, it may be necessary to employ surgical procedures. The procedures include percutaneous sperm aspiration from either the epididymis or the testis, and surgical sperm retrieval either by conventional or microsurgical means. The details of these methods are described in separate chapters.

The procedures sometimes result in hematomas and pain, while serious complications, including injury to the arteries and partial testicular infarction or permanent testicular devascularization, are rare. ${ }^{101,102}$ Sperm obtained from sperm retrieval methods are employed in ARTs. This can be done immediately after extraction or the sperm can be cryopreserved and used at a later time. The latter can potentially spare the patient from repeated surgeries and may avoid hormonal treatment of the female if no sperm can be retrieved.

\section{Choice of assisted ejaculation/sperm retrieval technique}

As mentioned previously, the first choice in neurological anejaculation should be assisted ejaculation. The more expensive and more invasive procedures of aspiration and surgery should only be used if both PVS and EEJ have failed. In an analysis of 3152 procedures in $500 \mathrm{SCI}$ men, ejaculates were obtained with either PVS or EEJ in $97 \%$ of patients. The total motile sperm counts exceeded five million in $63 \%$ of cases. ${ }^{35}$ Because of lower cost, less invasiveness and a higher total motile sperm outcome than with EEJ, PVS is the first choice in SCI men and should always be attempted. Patients with other conditions, such as diabetes or MS, can benefit from EEJ under general anesthesia.

To the possible detriment of their patients, many practitioners are, however, omitting the assisted ejaculatory techniques and use surgical procedures as the first-line treatment. ${ }^{81}$ This is most likely due to a lack of knowledge and/or training regarding PVS and EEJ. Clinics that are not able to offer these treatments should, as a minimum, inform their patients of the option of PVS/EEJ and refer them upon request.

With a healthy female partner, the relative success rates, including time to pregnancy, with PVS and EEJ, depends on the total motile sperm count obtained and the ART chosen. SCI patients (in whom PVS/EEJ are most often performed) can benefit from the same reproductive techniques as other infertile couples with similar pregnancy rates. $^{81}$

\section{ARTs}

When sperm have been obtained-either from assisted ejaculation or from sperm retrieval methods-ARTs follow.

Methods include intravaginal insemination (IVI), intrauterine insemination (IUI) and in vitro fertilization (IVF)/intracytoplasmic sperm injection (ICSI). Assuming only a male factor in the couples' infertility, the choice of ART is made based on the total motile sperm count. If there are more than four million (and especially above 10 million) motile sperm, the simple and low-cost methods of IVI and IUI can be attempted. ${ }^{103,104}$ This is especially feasible after sperm have been harvested in retrograde ejaculation and when assisted ejaculatory procedures are used to obtain sperm. With lower numbers of sperm or after IVI/IUI failures, the more invasive and expensive techniques of IVF with or without ICSI are used. With surgical sperm retrieval methods, the motile sperm counts obtained are usually so low that they force the couple to start with IVF/ICSI.

\section{IVI}

IVI is a method in which PVS and self-insemination are combined in a fashion that allows couples with an SCI male partner to perform the insemination themselves in their own home. The treatment starts in the clinic where the feasibility of PVS is evaluated and the man is examined. If ejaculation is induced, the risk of $\mathrm{AD}$ is manageable and sufficient numbers of motile sperm are found in the ejaculate, IVI can be offered. The patient and/or his partner are then instructed in PVS and they obtain a PVS device to use at home. Here, the time of ovulation is monitored by basal body temperature or urinary-luteinizing hormone excretion kits. At that time, the ejaculate is collected in a non-spermicidal cup and injected into the vagina of the female partner with a needleless syringe. ${ }^{79}$ IVI studies have reported pregnancy rates of $25 \%-65 \%$ per couple. ${ }^{105-110}$

\section{IUI}

IUI is very similar to IVI, but is performed at the clinic. Here, semen is collected by PVS or EEJ. If indicated, sperm may also be retrieved from the bladder after retrograde ejaculation. Processing then takes place to 
isolate the most motile sperm. ${ }^{111}$ The sperm are injected into the uterine cavity, which bypasses the cervix so that a larger number of sperm reach the fallopian tubes, but the sperm must still be motile to reach the oocyte, ${ }^{112}$ The injection is done at the time of ovulation, which is sometimes induced by human chorionic gonadotropin.

Giving the female partner fertility drugs, such as anti-oestrogens or gonadotrophins, is termed ovarian stimulation and can increase the number of available oocytes, ${ }^{113}$ However, it is controversial whether this treatment improves IUI pregnancy rates in isolated male infertility $^{114,115}$ and it carries a risk of ovarian hyperstimulation syndrome and causes an increased rate of multiple pregnancies, which raises the perinatal mortality and the maternal morbidity. ${ }^{116-120}$

There are no general data on IUI success in patients with neurological ejaculatory dysfunction; however, IUI in couples with SCI male partners has resulted in pregnancies for approximately one in three couples. The total motile sperm count is the most important predictive factor. ${ }^{104,105,107,109,110}$

\section{IVF/ICSI}

IVF/ICSI always involves ovarian stimulation and a human chorionic gonadotropin administration to trigger ovulation. Oocytes are then retrieved transvaginally under the guidance of ultrasound. In simple IVF, the sperm and oocytes are mixed in Petri dishes where fertilization can occur. With ICSI, a single sperm is injected directly into the oocyte. This means that ICSI allows fertilization with very few nonfunctional sperm whereas IVF relies on adequate gamete interaction and oocyte penetration. ${ }^{121-123}$ After about 5 days of in vitro development, embryos are injected into the uterus for implantation. ${ }^{124}$

Again, there are no data on success rates for these methods in neurological patients in general. IVF and ICSI in couples with SCI male partners have shown pregnancy rates between 38\% and 100\% per couple. ${ }^{105-109,125-127}$

It is important to remember that IVF and ICSI procedures are invasive and costly, compared to IVI/IUI. Maternal risks include potential complications with oocyte retrieval, and the ovarian stimulation related risks mentioned previously.

\section{Psychological aspects}

While infertility is typically treated as a medical diagnosis that may be overcome using the various procedures outlined previously, the psychological impact of the inability to conceive naturally is often neglected.

An infertility diagnosis can have a negative impact on the psychological health of patients, both male and female, given that the diagnosis is often accompanied by a major change in lifestyle due to an increased number of medical appointments, the possibility of recurring medical procedures and a number of other issues involved in fertility treatments. ${ }^{128}$ While this impact is often more stressful for women than men, ${ }^{129-131}$ an increase in mood disorders, including depression, has been evident for both sexes. ${ }^{128,132}$

A recent review ${ }^{128}$ notes the under-representation of literature available regarding the psychological impact of infertility diagnoses on men's psychological health.

Even less is known regarding how infertility affects males within the populations discussed in this review. An editorial in Sexuality and Disability ${ }^{133}$ discussed both the medical and the psychosocial issues related to having an SCI and fertility, noting the importance of addressing both of these needs in patients and of being knowledgeable regarding recent innovations in fertility treatments. Also of importance is the negative impact that emotional issues can have on being able to conceive, with psychological stress being listed as a common reason for discontinuing fertility treatments. ${ }^{128,134}$

A study ${ }^{135}$ examined the psychological impact of an infertility diagnosis on war veterans, who had sustained SCI during the Iran-Iraq war, as compared to otherwise healthy infertile controls. Both groups showed negative psychological effects that may have been due to their fertility status, including anxiety and depression, as compared to rates in the normal population. Interestingly, the finding that the partners of the otherwise healthy infertile males reported being more anxious regarding the duration of infertility than the partners of the SCI males may provide insight into differences in the coping mechanisms between these groups. Infertility is typically a hidden disorder, in that its symptoms are not obvious until a couple attempts to conceive and is unsuccessful. In clinical groups, such as patients with an SCI or that have undergone trauma or surgeries, the knowledge that conception may not be natural and will require the use of fertility treatments may help psychologically prepare both the patient and his or her partner for the inevitable number of clinical visits associated with fertility treatments, as well as protect against the stressful nature of fertility cycles including the failure to conceive. This is not to say that SCI couples do not experience the negative mental strain that accompanies infertility as other infertile couples do; however, it does suggest that the psychological experience of infertility may differ when there is prior knowledge that the likelihood of conceiving naturally is low. Future studies are needed in order to gain a greater understanding of the psychological impact of infertility.

\section{CONCLUSION}

Neurological disorders can cause infertility through ED and ejaculatory dysfunction which can potentially cause severe psychological stress. However, several methods are available to help these patients father children. Methods to retrieve sperm include medications and/ or bladder harvest for retrograde ejaculation, as well as PVS, EEJ and several surgical sperm retrieval methods for anejaculation. These methods are combined with IVI and ARTs to produce high pregnancy success rates. The choice of both sperm retrieval and reproductive technique depends on the underlying neurological condition and the total motile sperm count. It is important to consider the individual patient and to opt for the most non-invasive and cost-effective treatments first.

\section{COMPETING FINANCIAL INTERESTS}

Dr Jens Sønksen is a Shareholder in Multicept A/S, Frederiksberg, Denmark.

1 Jones EE, DeCherney AH. The male reproductive system. In:Boron WFBoulpaep ELMedical Physiology Philadelphia, PA: Elsevier Science; 2003; 1122-40.

2 Hurt KJ, Musicki B, Palese MA, Crone JK, Becker RE et al. Akt-dependent phosphorylation of endothelial nitric-oxide synthase mediates penile erection. Proc Natl Acad Sci USA 2002; 99: 4061-6.

3 Giuliano F, Clement P. Neuroanatomy and physiology of ejaculation. Annu Rev Sex Res 2005; 16: 190-216.

4 Coolen LM, Allard J, Truitt WA, McKenna KE. Central regulation of ejaculation. Physiol Behav 2004; 83: 203-15.

5 Thomas AJ Jr. Ejaculatory dysfunction. Fertil Steril 1983; 39: 445-54.

6 Maizels M. Normal and anomalous development of the urinary tract. In: Walsh PC, Campbell MF, editors. Campbell's Urology Vol. 2. Philadelphia, PA: W. B. Saunders Co.; 1998; 1545-600.

7 Bohlen D, Hugonnet CL, Mills RD, Weise ES, Schmid HP. Five meters of $\mathrm{H}_{2} \mathrm{O}$ : the pressure at the urinary bladder neck during human ejaculation. Prostate 2000; 44: 339-41.

8 NIH Consensus Conference. Impotence. NIH Consensus Development Panel on Impotence. JAMA 1993; 270: 83-90. 
9 Yavetz H, Yogev L, Hauser R, Lessing JB, Paz G et al. Retrograde ejaculation. Hum Reprod 1994; 9: 381-6.

10 Colpi G, Weidner W, Jungwirth A, Pomerol J, Papp G et al. EAU guidelines on ejaculatory dysfunction. Eur Uro/ 2004; 46: 555-8.

11 OhI DA, Quallich SA, Sonksen J, Brackett NL, Lynne CM. Anejaculation and retrograde ejaculation. Urol Clin North Am 2008; 35: 211-20, viii.

12 Rees PM, Fowler CJ, Maas CP. Sexual function in men and women with neurological disorders. Lancet 2007; 369: 512-25.

13 Vinik Al, Maser RE, Mitchell BD, Freeman R. Diabetic autonomic neuropathy. Diabetes Care 2003; 26: 1553-79.

14 Dunsmuir WD, Holmes SA. The aetiology and management of erectile, ejaculatory, and fertility problems in men with diabetes mellitus. Diabet Med 1996; 13: 700-8.

15 Sexton WJ, Jarow JP. Effect of diabetes mellitus upon male reproductive function. Urology 1997; 49: 508-13.

16 Genuth S. Insights from the diabetes control and complications trial/epidemiology of diabetes interventions and complications study on the use of intensive glycemic treatment to reduce the risk of complications of type 1 diabetes. Endocr Pract 2006; 12 (Suppl 1): 34-41.

17 Agbaje IM, Rogers DA, McVicar CM, McClure N, Atkinson AB et al. Insulin dependant diabetes mellitus: implications for male reproductive function. Hum Reprod 2007 22: 1871-7.

18 Bartak V, Josifko M, Horackova M. Juvenile diabetes and human sperm quality. Int J Fertil 1975; 20: 30-2.

19 Padron RS, Dambay A, Suarez R, Mas J. Semen analyses in adolescent diabetic patients. Acta Diabetol Lat 1984; 21: 115-21.

20 Ali ST, Shaikh RN, Siddiqi NA, Siddiqi PQ. Semen analysis in insulin-dependent/noninsulin-dependent diabetic men with/without neuropathy. Arch Androl 1993; 30: 47 54.

21 Niven MJ, Hitman GA, Badenoch DF. A study of spermatozoal motility in type 1 diabetes mellitus. Diabet Med 1995; 12: 921-4.

22 Delfino M, Imbrogno N, Elia J, Capogreco F, Mazzilli F. Prevalence of diabetes mellitus in male partners of infertile couples. Minerva Urol Nefrol 2007; 59: 131-5.

23 La VS, Condorelli R, Vicari E, D'Agata R, Calogero AE. Diabetes mellitus and sperm parameters: a brief review. J Androl; e-pub ahead of print 7 April 2011; doi: 10.2164/ jandrol.111.0131935.

24 La VS. Seminal vesicles and diabetic neuropathy: ultrasound evaluation. J Androl 2011; 32: 478-83.

25 Bener A, Al-Ansari AA, Zirie M, Al-Hamaq AO. Is male fertility associated with type 2 diabetes mellitus? Int Urol Nephrol 2009; 41: 777-784.

26 La VS, Calogero AE, Condorelli R, Lanzafame F, Giammusso B et al. Andrologica characterization of the patient with diabetes mellitus. Minerva Endocrinol 2009 34: 1-9.

27 Bauer SB, Koff SA, Jayanthi VR. Voiding dysfunction in children: neurogenic and nonneurogenic. In: Walsh PC, Retik AB, Vaughan E Jr, Wein AJ, editors. Campbell's Urology. Philadelphia, PA: W. B. Saunders; 2002; 2231-83.

28 Boemers TM, van Gool JD, de Jong TP. Tethered spinal cord: the effect of neurosurgery on the lower urinary tract and male sexual function. Br J Urol 1995; 76: 747-51.

29 Decter RM, Furness PD 3rd, Nguyen TA, McGowan M, Laudermilch C et al. Reproductive understanding, sexual functioning and testosterone levels in men with spina bifida. J Urol 1997; 157: 1466-8.

30 Olek MJ. Multiple sclerosis-Part I. Overview, pathophysiology, diagnostic evaluation, and clinical parameters. J Am Osteopath Assoc 1999; 99: 574-88.

31 Lilius HG, Valtonen EJ, Wikstrom J. Sexual problems in patients suffering from multiple sclerosis. Scand J Soc Med 1976; 4: 41-4.

32 Haensch CA, Jorg J. Autonomic dysfunction in multiple sclerosis. J Neurol 2006; 253 Suppl 1: I3-9.

33 Safarinejad MR. Evaluation of endocrine profile, hypothalamic-pituitary-testis axi and semen quality in multiple sclerosis. J Neuroendocrinol 2008; 20: 1368-75.

34 Cavalla P, Rovei V, Masera S, Vercellino M, Massobrio M et al. Fertility in patients with multiple sclerosis: current knowledge and future perspectives. Neurol Sci 2006; 27 231-9.

35 Brackett NL, Ibrahim E, Iremashvili V, Aballa TC, Lynne CM. Treatment for ejaculatory dysfunction in men with spinal cord injury: an 18-year single center experience. J Urol 2010; 183: 2304-8.

36 Denil J, OhI DA, Menge AC, Keller LM, McCabe M. Functional characteristics of sperm obtained by electroejaculation. J Urol 1992; 147: 69-72.

37 Ohl DA, Menge AC, Jarow JP. Seminal vesicle aspiration in spinal cord injured men: insight into poor sperm quality. J Urol 1999; 162: 2048-51.

38 Brackett NL, Davi RC, Padron OF, Lynne CM. Seminal plasma of spinal cord injured men inhibits sperm motility of normal men. J Urol 1996; 155: 1632-5.

39 Brackett NL, Lynne CM, Aballa TC, Ferrell SM. Sperm motility from the vas deferens of spinal cord injured men is higher than from the ejaculate. J Urol 2000; 164: 712-5.

40 Basu S, Lynne CM, Ruiz P, Aballa TC, Ferrell SM et al. Cytofluorographic identification of activated T-cell subpopulations in the semen of men with spinal cord injuries. $J$ Androl 2002; 23: 551-6.

41 Aird IA, Vince GS, Bates MD, Johnson PM, Lewis-Jones ID. Leukocytes in semen from men with spinal cord injuries. Fertil Steril 1999; 72: 97-103.

42 Trabulsi EJ, Shupp-Byrne D, Sedor J, Hirsch IH. Leukocyte subtypes in electroejaculates of spinal cord injured men. Arch Phys Med Rehabil 2002; 83: 31-4.

43 Basu S, Aballa TC, Ferrell SM, Lynne CM, Brackett NL. Inflammatory cytokine concentrations are elevated in seminal plasma of men with spinal cord injuries. $J$ Androl 2004; 25: 250-4.
44 Cohen DR, Basu S, Randall JM, Aballa TC, Lynne CM et al. Sperm motility in men with spinal cord injuries is enhanced by inactivating cytokines in the seminal plasma. J Androl 2004; 25: 922-5.

45 Brackett NL, Cohen DR, Ibrahim E, Aballa TC, Lynne CM. Neutralization of cytokine activity at the receptor level improves sperm motility in men with spinal cord injuries. J Androl 2007; 28: 717-21.

46 Iremashvili VV, Brackett NL, Ibrahim E, Aballa TC, Lynne CM. A minority of men with spinal cord injury have normal semen quality — can we learn from them? A casecontrol study. Urology 2010; 76: 347-51.

47 Spinal cord injury facts and figures at a glance. J Spinal Cord Med 2010; 33: 439-40.

48 O'Connor P. Incidence and patterns of spinal cord injury in Australia. Accid Anal Prev 2002; 34: 405-15.

49 Rathore MF, Hanif S, Farooq F, Ahmad N, Mansoor SN. Traumatic spinal cord injuries at a tertiary care rehabilitation institute in Pakistan. J Pak Med Assoc 2008; 58: 53-7.

50 Kuptniratsaikul V. Epidemiology of spinal cord injuries: a study in the Spinal Unit, Siriraj Hospital, Thailand, 1997-2000. J Med Assoc Thai 2003; 86: 1116-21.

51 Exner G, Meinecke FW. Trends in the treatment of patients with spinal cord lesions seen within a period of 20 years in German centers. Spinal Cord 1997; 35: 415-9.

52 Rendell MS, Rajfer J, Wicker PA, Smith MD. Sildenafil for treatment of erectile dysfunction in men with diabetes: a randomized controlled trial. Sildenafil Diabetes Study Group. JAMA 1999; 281: 421-26.

53 Palmer JS, Kaplan WE, Firlit CF. Erectile dysfunction in spina bifida is treatable. Lancet 1999; 354: 125-6.

54 Giuliano F, Hultling C, El Masry WS, Smith MD, Osterloh IH et al. Randomized trial of sildenafil for the treatment of erectile dysfunction in spinal cord injury. Sildenafil Study Group. Ann Neurol 1999; 46: 15-21.

55 Maytom MC, Derry FA, Dinsmore WW, Glass CA, Smith MD et al. A two-part pilot study of sildenafil VIAGRA in men with erectile dysfunction caused by spinal cord injury. Spinal Cord 1999; 37: 110-6.

56 Derry FA, Dinsmore WW, Fraser M, Gardner BP, Glass CA et al. Efficacy and safety of oral sildenafil Viagra.in men with erectile dysfunction caused by spinal cord injury. Neurology 1998; 51: 1629-33.

57 Vidal J, Curcoll L, Roig T, Bagunya J. Intracavernous pharmacotherapy for management of erectile dysfunction in multiple sclerosis patients. Rev Neurol 1995; 23: 269-71.

58 Dinsmore WW, Gingell C, Hackett G, Kell P, Savage D et al. Treating men with predominantly nonpsychogenic erectile dysfunction with intracavernosal vasoactive intestinal polypeptide and phentolamine mesylate in a novel auto-injector system: a multicentre double-blind placebo-controlled study. BJU Int 1999; 83: 274-9.

59 Hirsch IH, Smith RL, Chancellor MB, Bagley DH, Carsello J et al. Use of intracavernous injection of prostaglandin E1 for neuropathic erectile dysfunction. Paraplegia 1994; 32. $661-4$.

60 Bodner DR, Lindan R, Leffler E, Kursh ED, Resnick MI. The application of intracavernous injection of vasoactive medications for erection in men with spinal cord injury. J Urol 1987; 138: 310-1.

61 Kapoor VK, Chahal AS, Jyoti SP, Mundkur YJ, Kotwal SV et al. Intracavernous papaverine for impotence in spinal cord injured patients. Paraplegia 1993; 31 675-7.

62 Nehra A, Barrett DM, Moreland RB. Pharmacotherapeutic advances in the treatment of erectile dysfunction. Mayo Clin Proc 1999; 74: 709-21.

63 Price DE, Cooksey G, Jehu D, Bentley S, Hearnshaw JR et al. The management of impotence in diabetic men by vacuum tumescence therapy. Diabet Med 1991; 8: 964-7

64 Lloyd EE, Toth LL, Perkash I. Vacuum tumescence: an option for spinal cord injured males with erectile dysfunction. SCI Nurs 1989: 6: 25-8.

65 Zasler ND, Katz PG. Synergist erection system in the management of impotence secondary to spinal cord injury. Arch Phys Med Rehabil 1989; 70: 712-6.

66 Denil J, Ohl DA, Smythe C. Vacuum erection device in spinal cord injured men: patient and partner satisfaction. Arch Phys Med Rehabil 1996: 77: 750-3.

67 Ganem JP, Lucey DT, Janosko EO, Carson CC. Unusual complications of the vacuum erection device. Urology 1998; 51: 627-31.

68 Mulcahy JJ, Carson CC III. Long-term infection rates in diabetic patients implanted with antibiotic-impregnated versus nonimpregnated inflatable penile prostheses: 7-year outcomes. Eur Urol 2011; 60: 167-72.

69 Dietzen CJ, Lloyd LK. Complications of intracavernous injections and penile prostheses in spinal cord injured men. Arch Phys Med Rehabil 1992; 73: 652-5.

70 Padma-Nathan $\mathrm{H}$, Kanellos $\mathrm{A}$. The management of erectile dysfunction following spinal cord injury. Semin Urol 1992; 10: 133-7.

71 Kamischke A, Nieschlag E. Update on medical treatment of ejaculatory disorders. Int $J$ Androl 2002; 25: 333-44

72 Gilja I, Parazajder J, Radej M, Cvitkovic P, Kovacic M. Retrograde ejaculation and loss of emission: possibilities of conservative treatment. Eur Urol 1994; 25: 226-8.

73 Crich JP, Jequier AM. Infertility in men with retrograde ejaculation: the action of urine on sperm motility, and a simple method for achieving antegrade ejaculation. Fertil Steril 1978: 30: 572-6.

74 Suominen JJ, Kilkku PP, Taina EJ, Puntala PV. Successful treatment of infertility due to retrograde ejaculation by instillation of serum-containing medium into the bladder. A case report. Int J Androl 1991; 14: 87-90.

75 Braude PR, Ross LD, Bolton VN, Ockenden K. Retrograde ejaculation: a systematic approach to non-invasive recovery of spermatozoa from post-ejaculatory urine for artificial insemination. Br J Obstet Gynaecol 1987; 94: 76-83.

76 Shangold GA, Cantor B, Schreiber JR. Treatment of infertility due to retrograde ejaculation: a simple, cost-effective method. Fertil Steril 1990; 54: 175-7. 
77 Okada H, Goda K, Koshida M, Kamidono S. Pregnancy by insemination of cryopreserved spermatozoa from a man with retrograde ejaculation: a case report. J Reprod Med 2004; 49: 389-91.

78 Sonksen J, Biering-Sorensen F, Kristensen JK. Ejaculation induced by penile vibratory stimulation in men with spinal cord injuries. The importance of the vibratory amplitude. Paraplegia 1994; 32: 651-60.

79 Brackett NL. Semen retrieval by penile vibratory stimulation in men with spinal cord injury. Hum Reprod Update 1999; 5: 216-22.

80 Sonksen J, Ohl DA. Penile vibratory stimulation and electroejaculation in the treatment of ejaculatory dysfunction. Int J Androl 2002; 25: 324-32.

81 Kafetsoulis A, Brackett NL, Ibrahim E, Attia GR, Lynne CM. Current trends in the treatment of infertility in men with spinal cord injury. Fertil Steril 2006; 86: 781-9.

82 Sonksen J. Assisted ejaculation and semen characteristics in spinal cord injured males. Scand J Urol Nephrol Supp/ 2003; 213: 1-31.

83 Wieder JA, Brackett NL, Lynne CM, Green JT, Aballa TC. Anesthetic block of the dorsa penile nerve inhibits vibratory-induced ejaculation in men with spinal cord injuries. Urology 2000; 55: 915-7.

84 Brackett NL, Ferrell SM, Aballa TC, Amador MJ, Padron OF et al. An analysis of 653 trials of penile vibratory stimulation in men with spinal cord injury. J Urol 1998; 159: 1931-4

85 Brackett NL, Kafetsoulis A, Ibrahim E, Aballa TC, Lynne CM. Application of 2 vibrators salvages ejaculatory failures to 1 vibrator during penile vibratory stimulation in men with spinal cord injuries. J Urol 2007; 177: 660-3.

86 Kafetsoulis A, Ibrahim E, Aballa TC, Goetz LL, Lynne CM et al. Abdominal electrical stimulation rescues failures to penile vibratory stimulation in men with spinal cord injury: a report of two cases. Urology 2006; 68: 204-11.

87 Blanchard-Dauphin A, Rigot JM, Thevenon A. Treatment of ejaculation disorders by midodrine (Gutron) per os. Retrospective study of about 16 subjects. Ann Readapt Med Phys 2005; 48: 34-40. French.

88 Courtois FJ, Charvier KF, Leriche A, Vezina JG, Cote M et al. Blood pressure changes during sexual stimulation, ejaculation and midodrine treatment in men with spinal cord injury. BJU Int 2008; 101: 331-7.

89 Giuliano F, Rubio-Aurioles E, Kennelly M, Montorsi F, Kim ED et al. Vardenafil improves ejaculation success rates and self-confidence in men with erectile dysfunction due to spinal cord injury. Spine (Phila Pa 1976) 2008; 33: 709-15.

90 Ekland MB, Krassioukov AV, McBride KE, Elliott SL. Incidence of autonomic dysreflexia and silent autonomic dysreflexia in men with spinal cord injury undergoing sperm retrieval: implications for clinical practice. J Spinal Cord Med 2008; 31: 33-9.

91 Elliott S, Krassioukov A. Malignant autonomic dysreflexia in spinal cord injured men. Spinal Cord 2006; 44: 386-92.

92 Sheel AW, Krassioukov AV, Inglis JT, Elliott SL. Autonomic dysreflexia during sperm retrieval in spinal cord injury: influence of lesion level and sildenafil citrate. J Appl Physiol 2005; 99: 53-8.

93 Steinberger RE, OhI DA, Bennett CJ, McCabe M, Wang SC. Nifedipine pretreatment for autonomic dysreflexia during electroejaculation. Urology 1990; 36: 228-31.

94 Sonksen J, Ohl DA, Wedemeyer G. Sphincteric events during penile vibratory ejaculation and electroejaculation in men with spinal cord injuries. J Urol 2001; 165: 426-9.

95 Brackett NL, Ead DN, Aballa TC, Ferrell SM, Lynne CM. Semen retrieval in men with spinal cord injury is improved by interrupting current delivery during electroejaculation. J Urol 2002; 167: 201-3.

96 OhI DA, Sonksen J, Menge AC, McCabe M, Keller LM. Electroejaculation versus vibratory stimulation in spinal cord injured men: sperm quality and patient preference. J Urol 1997; 157: 2147-9.

97 Perkash I, Martin DE, Warner H, Blank MS, Collins DC. Reproductive biology of paraplegics: results of semen collection, testicular biopsy and serum hormone evaluation. J Urol 1985; 134: 284-8.

98 Sarkarati M, Rossier AB, Fam BA. Experience in vibratory and electro-ejaculation techniques in spinal cord injury patients: a preliminary report. J Urol 1987; 138: 59-62.

99 Brackett NL, Padron OF, Lynne CM. Semen quality of spinal cord injured men is better when obtained by vibratory stimulation versus electroejaculation. J Urol 1997; 157: $151-7$

100 Iremashvili V, Brackett NL, Ibrahim E, Aballa TC, Lynne CM. The choice of assisted ejaculation method is relevant for the diagnosis of azoospermia in men with spinal cord injuries. Spinal Cord 2011; 49: 55-9.

101 Practice Committee of the American Society for Reproductive Medicine. Sperm retrieval for obstructive azoospermia. Fertil Steril 2008; 90: S213-8.

102 Schlegel PN, Su LM. Physiological consequences of testicular sperm extraction. Hum Reprod 1997; 12: 1688-92.

103 van Voorhis BJ, Barnett M, Sparks AE, Syrop CH, Rosenthal G et al. Effect of the total motile sperm count on the efficacy and cost-effectiveness of intrauterine insemination and in vitro fertilization. Fertil Steril 2001; 75: 661-8.

104 Ohl DA, Wolf LJ, Menge AC, Christman GM, Hurd WW et al. Electroejaculation and assisted reproductive technologies in the treatment of anejaculatory infertility. Fertil Steril 2001; 76: 1249-55

105 Sonksen J, Sommer P, Biering-Sorensen F, Ziebe S, Lindhard A et al. Pregnancy after assisted ejaculation procedures in men with spinal cord injury. Arch Phys Med Rehabil 1997; 78: 1059-61.

106 Lochner-Ernst D, Mandalka B, Kramer G, Stohrer M. Conservative and surgical semen retrieval in patients with spinal cord injury. Spinal Cord 1997; 35: 463-8.
107 Nehra A, Werner MA, Bastuba M, Title C, Oates RD. Vibratory stimulation and rectal probe electroejaculation as therapy for patients with spinal cord injury: semen parameters and pregnancy rates. J Urol 1996; 155: 554-9.

108 Dahlberg A, Ruutu M, Hovatta 0. Pregnancy results from a vibrator application, electroejaculation, and a vas aspiration programme in spinal-cord injured men. Hum Reprod 1995; 10: 2305-7.

109 Rutkowski SB, Geraghty TJ, Hagen DL, Bowers DM, Craven M et al. A comprehensive approach to the management of male infertility following spinal cord injury. Spinal Cord 1999; 37: 508-14.

110 Kathiresan AS, Ibrahim E, Aballa TC, Attia GR, Lynne CM et al. Pregnancy outcomes by intravaginal and intrauterine insemination in 82 couples with male factor infertility due to spinal cord injuries. Fertil Steril 2011; 96: 328-31.

111 Boomsma CM, Heineman MJ, Cohlen BJ, Farquhar C. Semen preparation techniques for intrauterine insemination. Cochrane Database Syst Rev 2007; 4: CD004507.

112 Duran EH, Morshedi M, Taylor S, Oehninger S. Sperm DNA quality predicts intrauterine insemination outcome: a prospective cohort study. Hum Reprod 2002; 17: 3122-8.

113 Cantineau AE, Cohlen BJ, Heineman MJ. Ovarian stimulation protocols antioestrogens, gonadotrophins with and without GnRH agonists/antagonists. for intrauterine insemination IUI in women with subfertility. Cochrane Database Syst Rev 2007; 2: CD005356.

114 Bensdorp AJ, Cohlen BJ, Heineman MJ, Vandekerckhove P. Intra-uterine insemination for male subfertility. Cochrane Database Syst Rev 2007; 4: CD000360.

115 Goverde AJ, McDonnell J, Schats R, Vermeiden JP, Homburg R et al. Ovarian response to standard gonadotrophin stimulation for IVF is decreased not only in older but also in younger women in couples with idiopathic and male subfertility. Hum Reprod 2005; 20: $1573-7$.

116 Yeh J, Leipzig S, Friedman EA, Seibel MM. Results of in vitro fertilization pregnancies: experience at Boston's Beth Israel Hospital. Int J Fertil 1990; 35: 116-9.

117 Navot D, Bergh PA, Laufer N. Ovarian hyperstimulation syndrome in novel reproductive technologies: prevention and treatment. Fertil Steril 1992; 58: 249-61.

118 Assisted reproductive technology in the United States: 1996 results generated from the American Society for Reproductive Medicine/Society for Assisted Reproductive Technology Registry. Fertil Steril 1999; 71: 798-807.

119 Schenker JG, Ezra Y. Complications of assisted reproductive techniques. Fertil Steril 1994: 61: 411-22.

120 Fauser BC, Devroey P, Macklon NS. Multiple birth resulting from ovarian stimulation for subfertility treatment. Lancet 2005 ; 365 : 1807-16.

121 Palermo G, Joris H, Devroey P, van Steirteghem AC. Pregnancies after intracytoplasmic injection of single spermatozoon into an oocyte. Lancet 1992; 340: 17-8.

122 Kupker W, Schlegel PN, Al-Hasani S, Fornara P, Johannisson R et al. Use of frozenthawed testicular sperm for intracytoplasmic sperm injection. Fertil Steril 2000; 73 : 453-8.

123 Cohen J, Garrisi GJ, Congedo-Ferrara TA, Kieck KA, Schimmel TW et al. Cryopreservation of single human spermatozoa. Hum Reprod 1997; 12: 994-1001.

124 della RT, Verheyen G, Papanikolaou EG, van LL, Devroey P et al. Developmental stage on day- 5 and fragmentation rate on day- 3 can influence the implantation potential of top-quality blastocysts in IVF cycles with single embryo transfer. Reprod Biol Endocrinol 2007; 5: 2

125 Hultling C, Rosenlund B, Levi R, Fridstrom M, Sjoblom P et al. Assisted ejaculation and in-vitro fertilization in the treatment of infertile spinal cord-injured men: the role of intracytoplasmic sperm injection. Hum Reprod 1997; 12: 499-502.

126 Heruti RJ, Katz H, Menashe Y, Weissenberg R, Raviv G et al. Treatment of male infertility due to spinal cord injury using rectal probe electroejaculation: the Israeli experience. Spinal Cord 2001; 39: 168-75

127 Shieh JY, Chen SU, Wang YH, Chang HC, Ho HN et al. A protocol of electroejaculation and systematic assisted reproductive technology achieved high efficiency and efficacy for pregnancy for anejaculatory men with spinal cord injury. Arch Phys Med Rehabil 2003; 84: 535-40

128 Cousineau TM, Domar AD. Psychological impact of infertility. Best Pract Res Clin Obstet Gynaecol 2007; 21: 293-308.

129 Edelmann RJ, Connolly KJ. Psychological state and psychological strain in relation to infertility. J Community App/ Soc Psychol 1998; 8: 303-11.

130 Jordan C, Revenson TA. Gender differences in coping with infertility: a meta-analysis. J Behav Med 1999; 22: 341-58

131 Verhaak CM, Smeenk JM, van Minnen A, Kremer JA, Kraaimaat FW. A longitudinal, prospective study on emotional adjustment before, during and after consecutive fertility treatment cycles. Hum Reprod 2005; 20: 2253-60.

132 Volgsten H, Skoog Svanberg A, Ekselius L, Lundkvist O, Sundström Poromaa I. Prevalence of psychiatric disorders in infertile women and men undergoing in vitro fertilization treatment. Hum Reprod 2008; 23: 1056-63.

133 Ducharme S. From the Editor: Medical and psychosocial aspects of infertility for men with spinal cord injury and their partners. Sex Disabil 2006; 24: 73-5.

134 Kraaij V, Garnefski N, Schroevers MJ, Weijmer J, Helmnerhorst F. Cognitive coping, goal adjustment, and depressive and anxiety symptoms in people undergoing infertility treatment: a prospective study. J Health Psych 2010; 15: 876-86.

135 Karimzadeh M, Salsabili N, Akbariasbagh F, Mehrsai A. The psychological impact of infertility in the male able bodied and spinal cord injured population. Sex Disabil 2006; 24: 185-93. 